\title{
REDES GEOGRÁFICAS E A CAPILARIZAÇÃo DO CONTEÚDO URBANO
}

\author{
Elizabete dos Santos ${ }^{1}$ \\ Celso Donizete Locatel ${ }^{2}$
}

\section{Resumo}

A urbanização é um dos processos mais antigos da história. Contudo, ela ganha novas variáveis ao longo do tempo e especificidades de acordo com o lugar em que ocorre. $\mathrm{O}$ período técnico-científico-informacional traz inovações decorrentes do avanço da técnica, da ciência e da informação que foram potencializadas em função do aumento das redes pelo território. Tais redes tem contribuído para a capilarização do conteúdo urbano, alterando a relação entre as cidades e redefinindo as hierarquias urbanas. Esse artigo tem o objetivo de discutir de que forma as redes geográficas do período técnico-científicoinformacional promovem a capilarização do conteúdo urbano em diferentes densidades pelo território, redefinindo a rede urbana. Para isso o território norte-rio-grandense é considerado como recorte espacial para fins de análise.

Palavras-chave: Território, rede, urbanização, conteúdo urbano e Rio Grande do Norte.

\section{GEOGRAPHIC NETWORKS AND THE CAPILLARIZATION OF URBAN CONTENT}

\begin{abstract}
Urbanization is one of the oldest processes in human history. However, it gains new variables over time and specificities according to the place where it occurs. The technicalscientific-informational period brings innovations resulting from the advancement of technique, science and information that were enhanced due to the increase in networks across the territory. Such networks have contributed to the capillarization of urban content, changing the relationship between cities and redefining urban hierarchies. This article aims to discuss how the geographic networks of the technical-scientific-informational period promote the capillarization of urban content in different densities across the territory, redefining the urban network. For this purpose, the norteriograndense territory is considered as a spatial field for analysis purposes.
\end{abstract}

Keywords: Territory, network, urbanization, urban content and Rio Grande do Norte.

\footnotetext{
1 Doutoranda em Geografia pela Universidade Federal do Rio Grande do Norte. E-mail: elizabete.gurgel@gmail.com

2 Professor adjunto de Departamento de Geografia da Universidade Federal do Rio Grande do Norte DGE/CCHLA/UFRN. Docente permanente do Programa de Pós-graduação e Pesquisa em Geografia da Universidade Federal do Rio Grande do Norte - PPGe/UFRN. Email: celso.locatel@ufrn.br
} 


\section{REDES GEOGRÁFICAS Y CAPILARIZACIÓN DE CONTENIDOS URBANOS}

\section{Resumen}

La urbanización es uno de los procesos más antiguos de la historia de la humanidad. No obstante su longevidad, la urbanización incrementa nuevas variables a lo largo del tiempo y gana especificidades según el lugar donde ocurre. El período técnico-científicoinformativo trae innovaciones producto del avance de la técnica, la ciencia y la información que se potenciaron con el aumento de las redes en todo el territorio. Estas redes han contribuido a la capilarización del contenido urbano, cambiando la relación entre ciudades y redefiniendo las jerarquías urbanas. Este artículo tiene como objetivo discutir cómo las redes geográficas del período técnico-científico-informativo promueven la capilarización de contenidos urbanos en diferentes densidades a lo largo del territorio, redefiniendo la red urbana. A tal efecto, el territorio norteriograndense se considera un recorte espacial a efectos de análisis.

Palabras clave: Territorio, red, urbanización, contenidos urbanos y Rio Grande do Norte.

\section{INTRODUÇÃO}

A urbanização é um dos processos mais antigos registrados na história. No entanto, as características desse processo apresentam mudanças em função do lugar em que ocorrem e do próprio tempo. Seja ele, o tempo cronológico já que existe um movimento de urbanização global que se diferencia a partir das inovações e limitações técnicas de cada época, seja em função do tempo dos lugares que se dá em virtude das diferentes configurações territoriais de cada porção do espaço, as quais servem de entraves ou catalizadores do processo.

Assim, descrever a urbanização na idade antiga ou na idade média é bem diferente de descrevê-la na idade moderna ou contemporânea. Nesse artigo, as atenções serão voltadas a discutir as características da urbanização no período técnico-científicoinformacional. Investigar o que esse período traz de inovações que provocaram um acontecer diferente do processo de urbanização de hoje do de outrora, em que medida que a técnica, a ciência e a informação potencializaram a capilarização do conteúdo urbano pelo espaço.

No Brasil o período técnico-científico-informacional se inicia na década de 1970, conforme SANTOS (2009), porém no Rio Grande do Norte o meio técnico científico informacional só vai se configurar como tal a partir da década de 1990, quando as 
características do período em questão passam a se expandir, desigualmente, mas de forma combinada, pelo estado.

Os seguintes questionamentos nortearam essa discussão: Como as redes geográficas contribuem para a capilarização do conteúdo urbano? No período técnico científicoinformacional a capilarização do conteúdo urbano se dá na mesma intensidade e temporalidade em todos os lugares? Como essa capilarização do urbano, potencializado pela densidade das redes promove uma redefinição da rede urbana potiguar? Na busca de possíveis respostas ou pelo menos de promover uma discussão sobre o tema, o objetivo desse artigo é discutir de que forma as redes geográficas do período técnico-científicoinformacional promovem a capilarização do conteúdo urbano em diferentes densidades pelo território, redefinindo a rede urbana. Para isso o território norteriograndense será considerado como recorte espacial para fins de análise.

Logo, o artigo aborda o tema em questão por meio do uso de concepções teóricas geográficas e o estudo de caso do Rio Grande do Norte. O estado em questão foi selecionado em função de sua complexa e emblemática rede urbana, com cidades que possuem um forte poder de polarização em escala regional e diversas cidades de influência apenas local, as quais estabelecem relação não só com o centro regional, mas também com a capital do estado e outros grandes centros urbanos regionais localizados fora do estado e até mesmo grandes centros nacionais e internacionais. A inexistência de uma hierarquia bem definida e intransponível onde, a cidade local se relaciona com o centro regional, com o centro nacional e com grandes centros urbanos estrangeiros é uma das características da rede urbana potiguar no atual período.

A pesquisa está sustentada no levantamento, tratamento e análise de dados secundários, elaboração cartográfica e pesquisa documental. Também foram consultados os principais relatórios do IBGE que analisam a hierarquia das cidades, não para apontar a existência de uma nova hierarquia mas para perceber como as novas variáveis da urbanização no meio técnico-científico-informacional promovem dinâmicas diferentes na relação entre as cidades.

\section{AS REDES GEOGRÁFICAS}

O conceito de rede tem sido cada vez mais discutido na ciência geográfica, sendo certamente um de seus conceitos basilares. Corrêa define redes geográficas como sendo "o 
conjunto de localizações humanas articuladas entre si por meio de vias e fluxos". (CORRÊA,2011, p.200) Sendo para ele a rede urbana considerada a mais importante manifestação das redes geográficas, o que ocorre em função de sua complexidade, já que a rede urbana é formada a partir da combinação de uma série de outras redes, com pontos e nós sobrepostos.

A urbanização enquanto processo demanda continuamente a construção de vias que viabilizem os fluxos de que ela necessita para continuar se desenvolvendo. Não apenas fluxos de mercadorias, de capital e de pessoas, mas também fluxos imateriais, como os informacionais, que tem adquirido cada vez mais densidade no período técnico científico informacional. Por isso, compreender as redes geográficas é primordial na análise urbana do atual período.

As redes geográficas produzem uma divisão territorial do poder e do trabalho (CORREA, 2011, p.201), logo a sua existência muda a hierarquia das cidades, já que ao mudar uma rede geográfica, muda-se a relação de poder entre os lugares e consequentemente ocorre a redefinição da hierarquia entre eles. A expansão da cobertura de internet pelo território brasileiro das últimas décadas, por exemplo, tem contribuído para o crescimento da modalidade de compras realizada on line, na qual a distância física é relativizada ao passo que um consumidor pode realizar uma compra em um município do interior do país, com menos de 5 mil habitantes e receber em sua casa um produto oriundo de um grande centro urbano de influência nacional como São Paulo ou até mesmo de outros países. Essa transação ocorre sem demandar a intermediação de um município de influência regional, havendo assim uma flexibilização da relação de poder entre os municípios pequenos e os centros regionais.

Assim, é possível afirmar que a divisão territorial do trabalho do século XXI tem como uma de suas características atuais a fragmentação da produção, o parcelamento da distribuição e a pulverização do consumo, o que só se torna possível em função do adensamento das redes no território. Portanto, o conceito de redes ganha uma nova conotação no período atual, fruto de uma dinâmica organizacional diferenciada. Castells (1999) afirma que embora as redes tenham existido em outros tempos, com formas de organização diferentes, hoje elas se constituem enquanto uma nova morfologia social nas sociedades contemporâneas já que o "novo paradigma da tecnologia da informação fornece 
a base material para sua expansão penetrante em toda a sua estrutura social" (CASTELLS,1999, p. 497).

Concorda-se com Dias (2005, p. 12) quando esta afirma que a rede, devido a multiplicação de técnicas reticulares, tornou-se uma "forma privilegiada de representar a realidade contemporânea", visto que "fluxos de toda ordem tornaram-se mais espessos, ampliando as necessidades de circulação e exigindo técnicas cada vez mais eficazes. Logo, essas redes geram novos nexos, mudando os usos do território e a relação do homem com o lugar.

As redes promovem uma capilarização do conteúdo urbano pelo território em diferentes densidades, já que a urbanização enquanto um processo vai ocorrer no território como um todo mas se manifesta de forma desigual em virtude das especificidades de cada lugar. Portanto, o mais viável na análise urbana atual é se falar em densidades do urbano e não em áreas urbanas e áreas rurais. Até porque o urbano e o rural são conteúdos que coexistem no espaço, e apesar de opostos não são excludentes. Principalmente para fins de planejamento o que importa não é estabelecer uma fronteira de separação entre o espaço urbano e o espaço rural, mas compreender qual o grau de urbanização de cada porção de território. Pois assim, se torna possível analisar quais as demandas de políticas e ações correspondentes a cada grau de urbanização, afim de potencializar a eficácia dessas políticas.

As redes geográficas e os fluxos, que são por ela viabilizados e potencializados, tem gerado cada vez mais uma racionalidade do consumo e consequentemente uma mudança no modo de vida das pessoas, que seguem um padrão global. Todavia, se diferenciam no lugar ao encontrar especificidades materiais e imateriais, como a cultura, a materialidade urbana, os níveis de renda, grau de escolaridade, o nível de conectividade, as normas consuetudinárias (SANTOS, 2009), entre outros.

As redes, portanto, "integram e desintegram, destroem velhos recortes espaciais e criam novos" (Santos, 2009, p. 263). Elas viabilizam a ocorrência dos novos usos do território, mas também contribuem com a ressignificação de velhos usos.

Sobre a relação entre redes e urbanização pode-se dizer que as redes dão o ritmo a urbanização. Quando densas elas potencializam o acontecer urbano, mas quando rarefeitas elas representam um entrave ao processo. Isso porque as 
"redes organizadas hierarquicamente permitem assegurar o controle sobre aquilo que pode ser distribuído, alocado e/ou possuído. Permitem ainda impor e manter uma ou várias ordens. Enfim, permitem realizar a integração e a coesão dos territórios. Esses sistemas constituem o invólucro no qual se originam as relações de poder" (RAFFESTIN, 1993, p. 151).

Assim, uma porção do território densamente interligada por redes representa uma área para onde os fluxos convergem, onde chegam e saem mercadorias, pessoas, informações, é uma área de forte influência e portanto de expressão de poder. Por isso, Raffestin (1993) sustenta que a rede se constitui como um sistema de linhas que formam tramas, em que a delimitação de um território, o controle dos pontos e o traçado das vias expressam as relações de poder, a partir de relações simétricas e dissimétricas entre os agentes envolvidos em sua constituição.

As redes viabilizam a capilarização do conteúdo urbano pelo território e é no período técnico-científico-informacional que essas redes tornam-se mais densas, proporcionando uma maior rapidez nos fluxos de mercadorias, pessoas e informações. Nesse sentido é fundamental discutir como a capilarização do conteúdo urbano, viabilizado pelas redes geográficas, ocorre no meio técnico-científico-informacional, acelerando o ritmo da urbanização.

\section{A CAPILARIZAÇÃO DO URBANO NO MEIO TÉCNICO-CIENTÍFICO- INFORMACIONAL}

Ao abordar a escolha metodológica de realizar uma periodização, que nada mais é do que a repartição do tempo em períodos, deve-se ter em mente a necessidade de se seguir uma lógica que perpassa por uma questão de método, e não apenas uma repartição aleatória. É preciso levar em consideração que a existência de um novo período pressupõe a ocorrência de eventos significativos que representem uma certa ruptura com algumas características do período anterior. O que não significa a ausência de algumas continuidades de características pretéritas, nem tampouco que esse novo período irá ocorrer em um mesmo tempo cronológico nos diferentes lugares.

Nesse sentido, ao abordar o período técnico-científico-informacional, comumente recorre-se a aspectos, cuja origem é anterior ao seu início, mas que por algum motivo são ressignificados ou potencializados no atual período. O início do período técnico-científicoinformacional se dá no pós-segunda guerra mundial, mas é apenas nos anos 1970 em que 
ocorre sua consolidação nos países do terceiro mundo. Tal período é caracterizado pela "profunda interação da ciência e da técnica, a tal ponto que certos autores preferem falar de tecnociência para realçar a inseparabilidade dos dois conceitos e das duas práticas" (SANTOS, 2009, p. 238)

Para Santos (2009), as características particulares desse período são: a união entre técnica e ciência passam a se dar cada vez mais sobre a égide do mercado, que se torna global; os objetos técnicos passam a ser objetos técnicos e também informacionais; a ciência, a tecnologia e a informação constituem a base da produção; dá-se a extensão do mundo artificial ao espaço rural; e, ocorre a cientificização e tecnicização da paisagem.

Esse é o período de banalização dos processos iniciados em décadas anteriores, como a modernização da agricultura, a disseminação da internet, a robótica. Há nesse estágio uma união sem precedentes entre técnica, ciência e informação que confere um caráter de universalidade ao meio geográfico. Contudo, as inovações desse período não são homogêneas nem tampouco simultâneas. Apesar de seguirem a um tempo global, essas inovações encontram no lugar as condições de sua expansão ou inércia.

Feitas essas ressalvas essa seção traz uma reflexão de quais diferenciações ocorrem no processo de urbanização no período técnico-científico-informacional. O que as características desse novo período agregam de novo ao processo em questão. A primeira constatação que pode ser feita no que se refere a urbanização nesse período, no território brasileiro, está na maior capilarização do conteúdo urbano, enquanto um conjunto de objetos e práticas sociais tipicamente urbanas, pelo território. O qual em função do avanço da técnica, da ciência e da informação se ramifica pelo território, em densidades diferentes, redefinindo a relação entre os lugares e a rede urbana.

Uma segunda constatação está no surgimento de novas variáveis e maior adesão de outras, como a expansão do acesso à internet, o e-commerce, a hipercapilaridade das finanças e do crédito, uma maior democratização da informação, promovida pela modernização e universalização dos sistemas de telecomunicações, entre outros. A banalização do uso dos smartphones, por exemplo, representam tanto um avanço no que diz respeito a expansão da informação, como também um avanço o que diz respeito a prestação de serviços, como serviços bancários, de compras, agendamento de serviços. As ações de comando enviadas através do uso de um smartphone gera fluxos imateriais e materiais, expandem o consumo, e até mesmo redefinem os fluxos. Segundo dados da 
Anatel (2020) no mês de maio de 2020 já existiam 225,3 milhões de celulares no Brasil, representando uma densidade de 106,36 celulares para cada 100 habitantes.

Por meio do acesso à informação de preços viabilizada pelo smartphone, o consumidor pode conseguir comprar um produto mais barato oriundo de um outro país, do que comprar um produto similar no comércio local por um preço mais elevado. Redefinindo assim, o cálculo tradicionalmente utilizado que defendia que quanto mais perto do mercado consumidor mais barato sairia o produto em função de uma diminuição no preço de deslocamento (frete). Outras variáveis passam a exercer maior influência sobre os preços, como: quantidade produzida, custo com mão de obra, impostos.

A densidade urbana traz consigo o imperativo da informação e a força da publicidade, já que a densidade populacional e técnica tornam as propagandas mais frequentes e visíveis. A cidade é o subespaço mais propício a realização de propagandas, haja vista que quanto mais visualizado um determinado anúncio for, maior será sua efetividade no sentido de potencializar as chances de ocorrência do consumo final. No Rio Grande do Norte é muito comum nas estradas, próximos a entrada das cidades de maior poder de polarização, se encontrar propagandas em outdoors de grandes marcas com mensagens de boas-vindas com o nome do município. O que é uma estratégia da marca para tornar mais visível e atrativa sua propaganda nesses municípios que, geralmente recebem mais visitantes, e portando, potenciais consumidores.

Assim, hoje, a produção do consumidor precede à produção dos bens e serviços, sobretudo quando se trata do consumo conspícuo, tratado por Contel (2006) como aquele consumo que não parte de uma necessidade efetiva, mas de um consumo voltado essencialmente para a manutenção do status social do indivíduo.

Outra variável da urbanização no meio técnico-científico informacional é uma maior conectividade provocada pela expansão das redes viárias e infoviárias. No Rio Grande do Norte essa conectividade se intensifica, no período técnico científico informacional, com a construção de novos trechos de estradas e revitalização de outros, o território torna-se mais fluido e o acesso aos municípios mais longínquos torna-se possível. Ocorre a expansão de trechos de rodovias estaduais e federais (BR-101, BR-226, BR-304, BR-405 e BR-406, BR-104, BR-427) que interligam as diferentes regiões do estado. Vale salientar que apesar da extensa cobertura de rodovias estaduais na malha viária do estado, 
$2.863 \mathrm{~km}$, uma grande parcela destas ainda não receberam pavimentação, apresentando uma estrutura precária. $\mathrm{O}$ que culmina em uma malha ferroviária densa, mas pouco fluida.

Ocorre também a expansão das infovias e das empresas de internet e telefonia pelos 167 municípios do estado, resultando em uma maior conectividade. Até mesmo em áreas eminentemente rurais se tem a instalação de torres de capitação de sinal de internet. Natal já conta com dezenas de empresas de internet, sendo as principais: Cabo Telecom, Brisanet, Net Virtua, Claro, Tim, Sky, Vivo, Hughes Net e Oi. O mercado dos municípios do interior é disputado entre diferentes empresas, as quais disponibilizam serviços de diferentes densidades técnicas, oferecendo desde internet a rádio até internet por fibras ópticas. Contudo, percebe-se uma intensa variação na qualidade e velocidade do sinal entre municípios, e até mesmo entre as áreas no interior de cada município. O que revela o caráter universal, mas não homogêneo da urbanização, evidenciando as contradições típicas do mundo capitalista.

Vale salientar que a constituição de redes não elimina as especificidades do lugar, muito pelo contrário, reafirmam-nas. Mas, o que se deve considerar é que agora a densidade técnica do lugar não é explicada apenas pela técnica que ele apresenta, mas também, pela sua relação com as cidades vizinhas, pelo seu grau de conectividade que é medido por meio das possibilidades de integração viária e informacional com uma cidade de maior densidade técnica. E, é dessa maneira, que no meio técnico científico informacional, o papel das cidades que se constituem enquanto polos regionais se intensificam, sendo criadas redes em torno dessas cidades polo, que redefinem inclusive o consumo e o acesso a serviços dos municípios menores.

Assim, a explicação da densidade técnica do município de Acari, que se constitui enquanto um município de baixa densidade técnica, localizado Seridó potiguar, não se explica mais apenas pelo que o município possui de técnica, mas também pela sua conectividade com os municípios circunvizinhos que possuem uma densidade técnica maior, a exemplo de Caicó e Currais Novos, os dois municípios de maior densidade técnica do Seridó. Isso porque o território é cada vez mais interligado por redes, e, assim, um mesmo indivíduo pode residir em Acari, trabalhar em Currais Novos e estudar em Caicó. Ao fazer suas compras, por mais que não exista uma rede de supermercado em seu município ele pode recorrer a um dos dois polos regionais para efetuar suas compras. 
Outro exemplo dessas especificidades reside no fato de que a grande maioria do estado do Rio Grande do Norte apresenta menos de 30\% de seus domicílios com acesso à internet banda larga (ANATEL, 2020), o que é um número bem baixo diante da realidade da região concentrada do Brasil. Quarenta e nove municípios, aproximadamente um terço dos 167 municípios do estado, apresentam menos de 6\% da população com acesso a esse serviço.

Ainda conforme dados da Anatel (2021), mas agora referentes ao ano corrente, no Brasil são 55,7 acessos à internet banda larga fixa para cada 100 domicílios, o que deixa a maior parte dos municípios norteriograndenses abaixo da média nacional. A média do Rio Grande do Norte é de 51,78 acessos à internet banda larga fixa para cada 100 domicílios. Apesar de estar abaixo da média nacional, o Rio Grande do Norte possui a maior média da região nordeste.

Assim, vale salientar que ocorre uma capilarização da internet pelo estado, mesmo que em densidades diferentes, atingindo inclusive a zona rural. Assim, apesar da capilarização do conteúdo urbano pelo território ser uma característica do período atual, a sua densidade é desigual, havendo áreas de rarefação e áreas de densidade.

\section{AS REDES NO PERÍODO TÉCNICO-CIENTÍFICO-INFORMACIONAL E A REDEFINIÇÃO DA REDE URBANA POTIGUAR}

Corrêa (2006, p. 7) define a rede urbana como o "conjunto funcionalmente articulado de centros urbanos e suas hinterlândias”. Essas últimas são as áreas que possuem uma necessidade de funções que não conseguem por si só suprir e, por isso, são atraídas pelas ofertas de funções de um determinado centro urbano que exerce assim um poder de polarização sobre as hinterlândias. As cidades não são autossuficientes e por isso, a noção de rede urbana ajuda de sobremaneira na compreensão das relações estabelecidas entre os centros urbanos e suas áreas de influência.

Conforme estudo de hierarquia urbana realizado por Christaller (1966), os centros urbanos que possuem um poder de centralidade definido em função da existência de funções são denominados de "lugares centrais". Tais centros possuem um "alcance espacial máximo, denominado por Christaller de maximum range, e um alcance espacial mínimo, denominado de minimum range, sendo que da combinação desses recortes 
espaciais é definida a área de influência de um determinado centro, em virtude de uma hierarquização entre as localidades centrais (CHRISTALLER, 1966).

No período técnico científico informacional continua havendo uma desigualdade no poder de polarização das cidades, porém já não há uma hierarquia tão bem delineada. A cidade local, por exemplo, não precisa mais necessariamente recorrer a um centro de influência regional para suprir determinada demanda, essa necessidade pode ser suprida pela própria metrópole nacional, em função de uma maior conexão promovida pela hipercapilarização das redes.

As inovações da urbanização no período técnico científico informacional, que só foram possíveis em função da expansão das redes geográficas, geram fixos e fluxos que promovem uma redefinição da relação entre os lugares, e portanto, da rede urbana. A hierarquia outrora existente, esfacela-se.

O IBGE vem realizando desde 1966 um estudo das regiões de influência das cidades (REGIC), com o intuito de conhecer as relações estabelecidas entre as cidades brasileiras com base na análise dos fluxos de bens e serviços. Com base nisso, elaborou-se um mapa com a hierarquia das cidades norteriograndense em quatro períodos, 1966, 1978, 2007 e 2018, última REGIC publicada. Esse mapa permite a análise de como a hierarquia das cidades foi modificada ao longo das décadas, conforme a metodologia do IBGE.

O estudo de 1987 utilizou a teoria das localidades centrais de Cristhaller como base da análise. Já no estudo de 2007, foram utilizados como principais fatores para a composição dos níveis hierárquicos dos centros a dimensão da região de influência de cada centro, a classificação dos centros de gestão do território e a intensidade de relacionamentos. Um diferencial desse estudo foi a criação da unidade de observação “Área de Concentração da População" (ACP), utilizada para cidades que se configuram enquanto grande aglomerado urbano. A ACP de Natal foi formada por Natal, Extremoz, Macaíba, Parnamirim, São José de Mipibu, São Gonçalo do Amarante e Nísia Floresta.

A edição de 2018 manteve o aporte teórico metodológico da edição de 2007, com o aprimoramento de alguns procedimentos e o acréscimo de pesquisas sobre temas relacionados. No atual estudo a rede urbana é estruturada a partir de duas dimensões, quais sejam: a hierarquia dos centros urbanos, dividida em cinco classes (Metrópoles, Capitais Regionais, Centros Sub-Regionais, Centros de Zona e Centros Locais); e as regiões de influências, definidas pela ligação das Cidades de menor para as cidades de maior 
hierarquia urbana. Essa última dimensão permite analisar de forma mais aprofundada a conectividade entre os municípios, o que é fundamental no estudo da urbanização no período atual.

Apesar dessa autora não acreditar na existência de uma hierarquia rígida entre as cidades, a análise temporal da região de influência das cidades possibilita reflexões importantes de como a rede urbana se redefine no período técnico científico informacional. Tal aspecto torna-se fundamental na análise dos geógrafos contemporâneos, sobretudo aqueles que trabalham com planejamento e ordenamento territorial. Com base nisso, foram elaborados quatro mapas com base em uma série histórica que mostra o resultado das principais classificações do IBGE para a hierarquia dos centros urbanos do Rio Grande do Norte, conforme figura 01.

O mapa 1A mostra que em 1966 Natal ocupava a posição de Centro Regional A na classificação da hierarquia urbana do IBGE, maior nível hierárquico do estado, seguido por Mossoró que apresenta o nível de Centro Regional B. O município que ocupa a terceira maior posição é Caicó que é considerado Centro sub-regional A, seguido por Currais Novos e Pau dos Ferros que eram Centro sub-regional B.

Na classificação de 1978, mapa 1B, Natal aparece como centro submetropolitano e Mossoró como capital regional. Caicó e Currais Novos parecem como centros subregionais, Pau dos Ferros que na classificação anterior era considerada Centro sub-regional B, nessa aparece apenas como centro de Zona, ao lado de outros municípios. Até porque na classificação de 1978 são considerados apenas quatro níveis hierárquicos, quais sejam: centro de zona, centro sub-regional, centro regional e centro submetropolitano.

Na classificação de 2007 são considerados 11 níveis hierárquicos para o território brasileiro, sendo eles: Grande metrópole nacional, Metrópole nacional, Metrópole, Capitais regionais A, B e C, Centros sub-regionais A e B, Centros de Zona A e B e centros locais, que são os municípios com população inferior a 10 mil habitantes. Logo, a partir de 2007 todos os municípios são classificados em algum nível hierárquico. Desses 11 níveis, o Rio Grande do Norte conta com 7, sendo o maior deles Capital Regional A, ocupado por Natal, seguido por Mossoró que passa a ser classificado como Capital Regional C.

Caicó e Pau dos Ferros aparecem como Centro sub-regional A, fazendo com que diferentemente da classificação de 1978, Pau dos Ferros assuma um nível hierárquico 
maior do que Currais Novos que aparece como Centro sub-regional B, junto à Açu. João Câmara e Macau aparecem como Centro de Zona A.

Alexandria, Apodi, Canguaretama, Parelhas, Passa e Fica, Patu, Santa Cruz, São Miguel, São Paulo do Potengi e Umarizal aparecem como Centro de Zona B. E os demais municípios como Centros Locais. Nessa classificação os centros de zona merecem destaque já que na última década do século XX e primeiros anos do século XXI iniciou-se um processo de modernização nas redes geográficas desses municípios, os quais também começaram a atrair objetos geográficos que aumentam seu poder de polarização, como estabelecimentos comerciais, estabelecimentos de serviços de educação e saúde, entre outros.

Essas cidades mudam sua função na hierarquia urbana, assumindo o papel de centros. Esse processo de modernização que se inicia nos anos 1990 vai encontrar densidade nas duas primeiras décadas do século XXI, resultando na configuração atual, expressa na última classificação de 2018. Nessa classificação aparecem os arranjos populacionais que são as grandes manchas urbanas, formadas por dois ou mais municípios. O qual é denominado de acordo com a unidade político-administrativa mais populosa, caso esta não supere o dobro da população dos demais municípios.

Por isso a classificação é dada para o arranjo populacional e não apenas para o município. O RN possui quatro arranjos populacionais, são eles: Caiçara do Norte, Natal, Santo Antônio e São José de Mipibu - Nísia Floresta/RN. A de Natal é formada por Natal, Parnamirim, Extremoz, Macaíba e São Gonçalo Amarante, sendo considerada como capital regional A. Os demais arranjos são considerados como centros locais. Mossoró sobe de Capital Regional C em 2007 para Capital Regional B em 2018. Caicó, Currais Novos, Açu e Pau dos Ferros são considerados centros sub-regionais B, havendo um declínio de nível em relação a classificação anterior para os municípios de Caicó e Pau dos Ferros que haviam sido considerados centros sub-regionais A.

O que se percebe é que com a capilarização das redes geográficas os centros regionais tradicionais (Caicó, Pau dos Ferros e Mossoró), perdem sua exclusividade no poder de polarização dos municípios vizinhos, fazendo emergir novos centros, como Currais Novos e Açu. Além disso, essa hierarquia não vai mais ser linear, obedecendo os níveis de maneira engessada, o centro local estabelece relação direta com a capital regional, com as metrópoles, com outros países, sem necessariamente ser intermediado 
pelo centro regional. A hierarquia, pode até permanecer para fins de classificação mas ela não mantém sua rigidez, muito pelo contrário, ela se torna flexível, volátil.

Figura 01: Classificação da Hierarquia Urbana do Rio Grande do Norte conforme o IBGE - Série Histórica
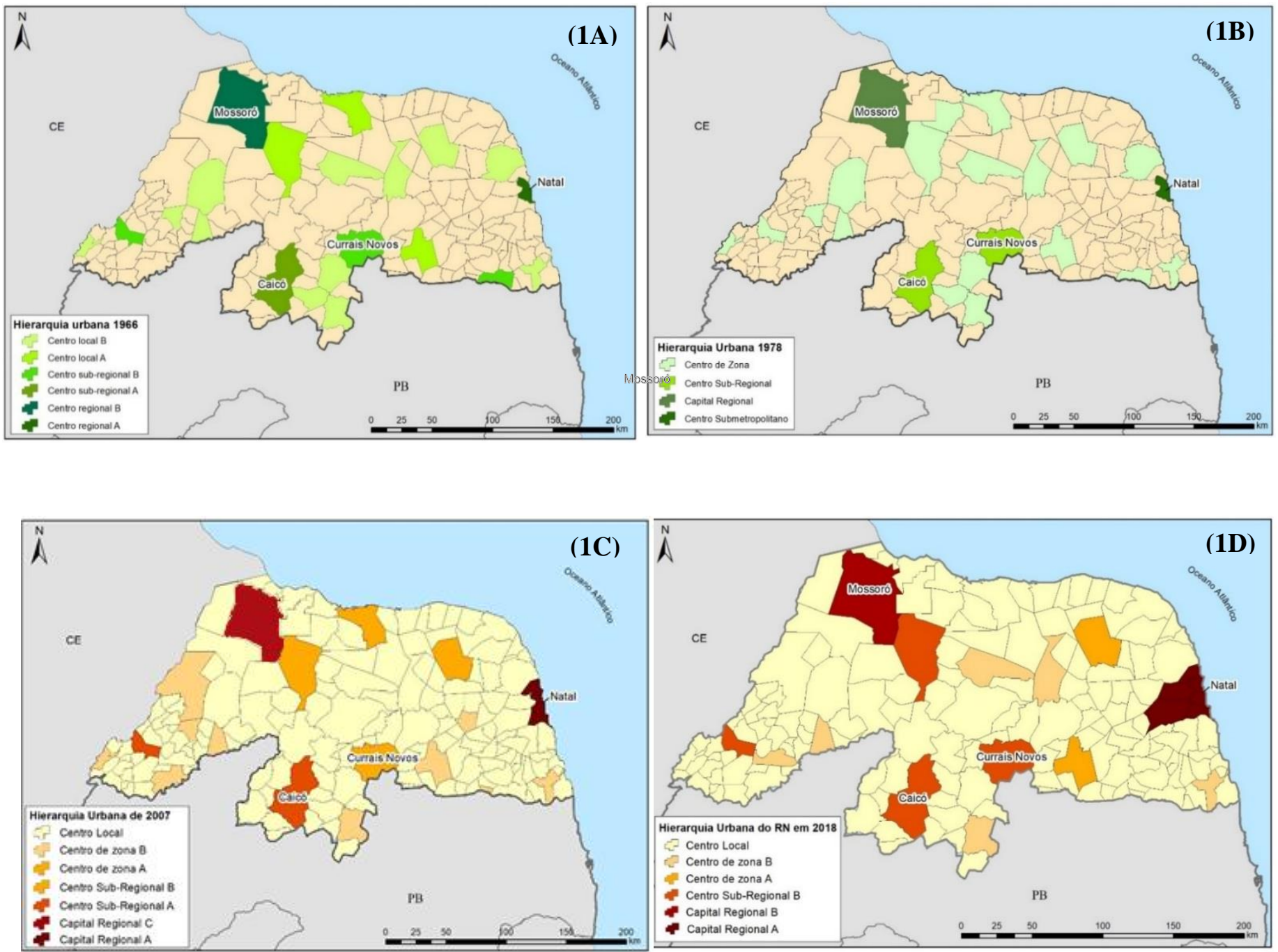

Autoria: Elizabete R.G Santos

Elaboração cartográfica: Ralyne E. C.Silva

Sistema de Coordenadas - SIRGAS 2000

Fonte: IBGE (1966, 1978, 2007, 2018)

Com o aumento do nível técnico nos municípios do RN e o surgimento de novos objetos geográficos, a capital do estado também passa a diminuir sua centralidade, já que demandas outrora só atendidas nesse município passam a ser oferecidas por outros centros urbano. Parnamirim, por exemplo, tem vivido nas últimas décadas um aumento expressivo 
no setor de serviços. Na última década o município atraiu faculdades e estabelecimentos que oferecem ensino técnico, como um Instituto Federal, fazendo com que sua população seja suprida no próprio município, diminuindo a dependência de Natal, e, atraindo estudantes de municípios vizinhos, que antes também iam para Natal, como Goianinha, Tibau do Sul, São José de Mipibu, Canguaretama entre outros.

Tavares (2017) sustenta que as redes constituídas a partir dos usos pretéritos do território potiguar resultaram em uma concentração de fixos, e por conseguinte, fluxos, nas principais centralidades do estado, o que reforça o papel histórico de polarização desempenhado por esses grandes centros urbanos. Tal fenômeno revela também uma dependência dos municípios menores em relação a esses centros.

No entanto, com a capilarização, ainda que desigual, das redes pelo território potiguar essa centralização, se mantém, mas em alguns casos diminui a partir do surgimento de novos fixos nos municípios menores, mas também de uma menor necessidade de deslocamento para alguns serviços, agora proporcionado pela internet. Serviços que outrora só podiam ser realizados em bancos, agora podem ser realizados através do celular ou computador. Compras que anteriormente exigiam o deslocamento dos consumidores até os estabelecimentos comerciais, hoje ocorrem mediante o deslocamento da própria mercadoria a partir dos serviços de entrega e de compras on line. O quadro 01 apresenta uma síntese de algumas características da rede urbana no período técnicocientífico-informacional.

O quadro 01 apresenta quatro aspectos que podem ser percebidos na rede urbana potiguar no período técnico científico informacional. Observa-se algumas mudanças, mas também muitas permanências. O conjunto de objetos construídos ao longo do tempo nos históricos centros regionais potiguares, formam uma configuração territorial favorável à manutenção de uma polarização desses em relação ao municípios de menor densidade técnica. Estes por sua vez, aumentaram seu nível técnico de urbanização, mas não a ponto de alterar as relações de centralidade da rede urbana potiguar e promover, nesse período, o surgimento de novos centros. 
Quadro 01: Características da rede urbana potiguar no período técnico científico informacional

\begin{tabular}{|c|c|}
\hline CARACTERÍSTICAS DA REDE URBANA POTIGUAR NO PERÍODO TÉCNICO- \\
CIENTÍFICO-INFORMACIONAL \\
$\begin{array}{c}\text { Aumento do nível } \\
\text { técnico da urbanização } \\
\text { dos centros locais }\end{array}$ & $\begin{array}{l}\text { Diminuição da necessidade de deslocamento para Natal a fim de } \\
\text { se ter acessos a alguns serviços e mercadorias mais simples, o que } \\
\text { ocorre em função do aumento do nível técnico da urbanização nos } \\
\text { municípios menores a partir da instalação de objetos geográficos. }\end{array}$ \\
\hline $\begin{array}{c}\text { Aumento do poder de } \\
\text { polarização dos centros } \\
\text { regionais }\end{array}$ & $\begin{array}{l}\text { Aumento da polarização exercida pelos centros urbanos de } \\
\text { influência regional, como Caicó, Mossoró, Pau dos Ferros, em } \\
\text { função da instalação de fixos, como Institutos Federais, } \\
\text { Universidades, Atacarejos, responsáveis por aumentar as } \\
\text { migrações pendulares. Esse fenômeno também promove e é } \\
\text { possibilitado pela expansão das linhas de transporte que fazem a } \\
\text { ligação desses municípios. }\end{array}$ \\
\hline $\begin{array}{c}\text { Manutenção dos centros } \\
\text { regionais históricos }\end{array}$ & $\begin{array}{l}\text { Manutenção dos centros regionais históricos fruto de um conjunto } \\
\text { de fixos pretéritos responsáveis por manter a centralidade, não } \\
\text { havendo a emergência de novos centros regionais nesse atual } \\
\text { período, mas a reafirmação dos mesmos centros historicamente } \\
\text { estabelecidos e aumento da polarização de alguns centros, mas não } \\
\text { a ponto de mudar drasticamente a rede urbana. } \\
\text { Diminuição da obrigatoriedade de deslocamentos de pessoas para } \\
\text { efetivação de compras e serviços, a compra pode ser efetuada pela } \\
\text { internet e a entrega exige apenas o deslocamento da mercadoria e } \\
\text { não do consumidor. }\end{array}$ \\
\hline $\begin{array}{c}\text { Aumento do E- } \\
\text { commerce e serviços de } \\
\text { frete }\end{array}$
\end{tabular}

As compras pela internet (E-commerce) tem provocado uma mudança no setor de comércio e de serviços no Rio Grande do Norte. No que se refere ao comércio, propriamente dito, a possibilidade de efetuar a compra on line e receber a mercadoria em casa, sem precisar do deslocamento do consumidor, tem resultado em uma movimentação do comércio, uma diminuição da necessidade de instalação de algumas lojas físicas e, no ramo alimentar os deliveries tem crescido significativamente. No setor de serviços, observa-se cada vez a diminuição da necessidade de deslocamento a agências bancárias, as quais, ausentes em muitos municípios, exigia o deslocamento de pessoas diariamente para centros urbanos que possuíam esse fixo. Além de outros serviços como contratação de internet e telefonia, pagamento de contas, os quais cada vez mais estão sendo realizados sem o deslocamento do consumidor.

A análise das últimas REGICs permite concluir que a rede urbana potiguar se redefiniu algumas vezes desde 1966 aos dias atuais e com certeza continuará se redefinindo. $\mathrm{O}$ aumento das redes geográficas, sejam elas viárias ou infoviárias, é o maior propulsor da compressão espaço-tempo do período atual, ela conecta lugares, diminui os 
tempos de deslocamentos, redefine o consumo. Elas dão o ritmo a capilarização do conteúdo urbano, ao mesmo tempo em que fornecem as bases desiguais para sua consolidação, mantendo assim, e até acentuando as diferenças entre os lugares.

\section{CONSIDERAÇÕES FINAIS}

A urbanização ganha novas proporções e elementos no período técnico científico informacional, sendo possível considerar a ocorrência de uma capilarização do conteúdo urbano pelo território brasileiro nesse período. No entanto, essa expansão do urbano ocorre de forma desigual e combinada, havendo áreas de densidade urbana e áreas de rarefação desse conteúdo. Logo, a questão em foco da Geografia não é mais identificar quais áreas são urbanas e quais áreas são rurais, mas trabalhar a coexistência desses conteúdos em uma mesma área, identificando a densidade de cada um desses conteúdos para um planejamento e gestão adequados.

A capilarização do urbano pelo território brasileiro foi possível em função da expansão das redes, sejam elas de natureza viárias, as quais possibilitam uma maior circulação de mercadorias e pessoas, sejam elas redes infoviárias que promovem um maior fluxo de informações. Sendo a informação uma variável chave para se compreender a urbanização do período técnico-científico-informacional. Por isso, considerar as redes na análise geográfica contemporânea se torna um desafio e uma necessidade na compreensão dos processos no período atual.

As inovações da urbanização no período técnico científico informacional, viabilizadas pela expansão das redes geográficas, geram fixos e fluxos que redefinem a relação entre os lugares, e, portanto, a rede urbana. A hierarquia urbana linear, outrora admitida, já não é mais regra, a rede urbana de complexificam, torna-se transponível e multiarticulada. O global penetra o local sem tantos intermediadores e, ao encontrar o lugar, redefine-se, sem homogeneizá-lo, mantendo, assim, suas particularidades

\section{REFERÊNCIAS}

ANATEL, 2020. Dados de acesso à internet no Brasil. Disponível em: https://www.teleco.com.br/ncel.asp, acesso em julho de 2020. 
ANATEL, 2021. Dados de acesso à internet no Brasil. .https://informacoes.anatel.gov.br/paineis/acessos/banda-larga-fixa, acesso em novembro de 2021.

CASTELLS, Manuel. A sociedade em rede. 2 ed. São Paulo: Paz e Terra, 1999.

CHRISTALLER, Walter. Central places in Southern Germany. New Jersey: Prentice Hall, 1966.

CONTEL, Fábio Betioli. Território e finanças: técnicas, normas e topologias bancárias no Brasil. Tese (Doutorado em Geografa) - Faculdade de Filosofa, Letras e Ciência Humanas, Universidade de São Paulo, São Paulo, 2006.

CORRÊA, Roberto Lobato. Redes Geográficas: Reflexões sobre um tema presente. São Paulo: Revista Cidades, 2011. Vol.9, n.16.

CORRÊA, R.L. Estudos sobre rede urbana. Rio de Janeiro: Bertrand Brasil, 2006. 330p.

DIAS, Leila Christina. Os sentidos da rede: notas para discussão. In: DIAS, Leila Christina. SILVEIRA, Rogério Leandro Lima da (Orgs.). Redes, sociedades e territórios. Santa Cruz do Sul: Edunisc, 2005.

RAFFESTIN, Claude. Por uma geografia do poder. São Paulo: Ática, 1993.

Regiões de influências das cidades - IBGE 2018. Disponivel em:

https://www.ibge.gov.br/geociencias/cartas-e-mapas/redes-geograficas/15798-regioes-deinfluencia-das-cidades.html?=\&t=sobre Acesso em: Agosto de 2020.

SANTOS, Milton. A natureza do espaço. Técnica e tempo. Razão e emoção. São Paulo: Edusp, 2009.

TAVARES, Edseisy Silva Barbalho. Usos do território e rede urbana potiguar. 2017. 448f. Tese (Doutorado em Geografia) - Centro de Ciências Humanas, Letras e Artes, Universidade Federal do Rio Grande do Norte, Natal, 2017.

Submetido em 04 de agosto de 2021

Aceito em 16 de novembro de 2021

Publicado em 30 de dezembro de 2021 